\title{
The Effect of Using a Powered Exoskeleton Training Programme on Joint Range of Motion on Spinal Injured Individuals: A Pilot Study
}

Hollie Samantha Forbes White ${ }^{1^{\star}}$, Stephen Hayes ${ }^{1}$ and Matthew White ${ }^{2}$

${ }^{1}$ Department of Sport Health and Exercise Science, University of Hull, Hull, East Yorkshire, HU6 7RX, United Kingdom ${ }^{2}$ Cyclone Technologies, Orchard House, Sunk Island Road, Ottringham, Hull, East Yorkshire, HU12 0DX, United Kingdom

\begin{abstract}
Background: Paralysis and loss of normal upright function is the most commonly acknowledged ongoing impairment related to spinal cord injury, although numerous co-morbidities exist. The risk and progress of some these conditions may be mitigated by upright function. Over-ground powered exoskeletons have the potential to provide many physical health benefits associated with upright mobility; however research into the specific effects of powered exoskeleton use on the joints does not yet exist. The ReWalk ${ }^{\mathrm{TM}}$ enables people with lower limb disabilities to carry out routine ambulatory functions such as walking, standing, sitting, and ascending/descending stairs. Changes in patients' joint range of motion as a consequence of one week of intensive powered exoskeleton training as part of a physiotherapy programme were investigated.
\end{abstract}

Methods: Sixteen participants aged 21-69 years with spinal cord injury between C3 and T12 (ASIA Impairment Scale A-D) visited the therapy centre. Passive range of motion of ankle dorsi-flexion, hip extension and shoulder internal rotation and extension was measured using goniometry. Participants then undertook the training programme which included use of parallel bars, crutches, different surfaces, and stairs/sitting/standing/walking. The programme is supplemented by the use of functional electrical stimulation, far-infrared heat therapy and physiotherapy for exercise preparation. After five days range of motion was re-measured. Paired t-tests were run on bilaterally averaged pre and post ranges of motion, accepted significance value was $\mathrm{p} \leq 0.05$.

Results: Mean dorsi-flexion increased from $1.7^{\circ}$ (plantigrade $\left.=0\right)$ to $6.9^{\circ}(\mathrm{t}(11)-6.3 ; \mathrm{p}<0.001)$. Mean hip extension increased from $8.2^{\circ}$ to $14.1^{\circ}(\mathrm{t}(13)-3.5 ; \mathrm{p}=0.017)$. There were no significant changes to shoulder extension (pre-64.7, post- $66.7^{\circ}, \mathrm{n}=9$ ) or shoulder internal rotation (pre-74.3, post-78. $9^{\circ}, \mathrm{n}=11$ ).

Conclusion: Although this was a pilot study and lacked a control condition, the addition of ReWalk ${ }^{\mathrm{TM}}$ technology was novel as part of a physiotherapy programme. Participation in the training programme appeared to result in significant increases in ankle dorsi-flexion and hip extension which may be beneficial for all types of ongoing upright weight-bearing therapy in this population.

\section{Background and Introduction}

In westernised societies the incidence of spinal cord injury (SCI) is between $15-40$ cases per million inhabitants $[1,2]$. In the UK SCI affects over 1000 new individuals every year and there are approximately 50,000 individuals living with SCI [3]. Following SCI the most commonly acknowledged impairment is paralysis and loss of upright function, however lesion level, lesion severity and type of nerve fibre damaged also dictate the full nature and permanency of the disability [3].

Rehabilitation of SCI aims to restore the maximum degree of independence and return individuals to normal activities of daily living [4] and health. Though many SCI individuals place a high degree of priority on restoration of walking [5] only $41-43 \%$ are able to do so [6]. To this end, over-ground powered exoskeleton technology has grown in popularity and availability, catering for individuals for whom walking and other activities relying on upright mobility (for example, standing and ascending/descending stairs) are not possible without assistance. Restoration of upright function may also have additional benefits for SCI individuals. Various sequelae exist alongside SCI including: increased risk of coronary heart disease [7], autonomic dysreflexia and increased risk of orthoststic hypotension [8], reduced postural control [9], reduced joint range of motion [10], reduced bone density [11] as well as various urinary, digestive, skeletal, respiratory, and integumentary dysfunction and disease [12]. Many sequelae are associated with long term wheel chair use and may be mitigated in onset and/or progression through the use of weight bearing exercise [12]. and function. E-mail: hollie.white@hull.ac.uk org/10.15344/2455-7498/2015/102 original author and source are credited.

\section{Publication History:}

Received: October 31, 2014

Accepted: November 24, 2014

Published: January 06, 2015

\section{Keywords:}

Exercise for spinal cord injury, Exoskeleton, Neurological Physiotherapy, Physiotherapy, ReWalk robotics, Spinal cord injury, Upright mobility, Weight bearing exercise efficacy of novel robotic technology on physiological parameters in an SCI population, especially those which may impact upon health

Previous research has mainly considered the effects of robotic assisted locomotion/gait in the form of robot assisted body weightsupported treadmill training $[13,14]$. Findings have been positive from this research, particularly for incomplete SCI individuals who have shown increased activity in the corticospinal tract after supported gait exercise, but also increased electromyogram activity and better walking (termed 'functional') outcome measures [13]. However no studies to date have reported the effects of a powered exoskeleton which has application for individuals with complete SCI and also provides propulsion as part of the generated gait cycle. Additionally, no studies were found that have focused on the physiological parameter of joint range of motion (ROM) to date.

"Corresponding Author: Dr. Hollie Samantha Forbes White, Department of Sport Health and Exercise Science, University of Hull, Hull, East Yorkshire, HU6 7RX, United Kingdom, Tel: +44 1482 463645, Fax: +44 1482463855;

Citation: White HSF, Hayes S, White M (2015) The Effect of Using a Powered Exoskeleton Training Programme on Joint Range of Motion on Spinal Injured Individuals: A Pilot Study. Int J Phys Ther Rehab 1: 102. doi: http://dx.doi.

Copyright: (c) 2015 White et al. This is an open-access article distributed under the terms of the Creative Commons Attribution License, which permits unrestricted use, distribution, and reproduction in any medium, provided the 
Citation: White HSF, Hayes S, White M (2015) The Effect of Using a Powered Exoskeleton Training Programme on Joint Range of Motion on Spinal Injured Individuals: A Pilot Study. Int J Phys Ther Rehab 1: 102. doi: http://dx.doi.org/10.15344/2455-7498/2015/102

With specific reference to the focus of our study, lower limb joint ROM is commonly reduced in SCI individuals [15] and requires regular stretching to maintain [16], particularly at the hip [17] and ankle [18]. Reduced ROM into hip extension can result in contractures which may cause dysplasia, dislocation and ankylosis of the hip joint [17]. Plantar flexion deformity as a result of increased tone, spasticity and stiffness is also common in SCI individuals [19] and reduced ROM into ankle dorsi-flexion may hinder upright functional activities due to a lack of clearance during gait and may also affect other common activities such as transfers [20]. Upper limb ROM is essential for function following SCI [21] and function of the upper limb is highly prioritised during acute and ongoing rehabilitation from SCI [4]. Shoulder internal rotation and extension may be particularly important for wheelchair propulsion because it is in this combined position that peak shoulder joint loading occurs during the push phase [22].

The aim of this study was to consider pilot data from use of the $\mathrm{ReWalk}^{\mathrm{TM}}$ as a new part of a five day physiotherapy programme aiming to train the user in the novel technology. Simple joint ROM in specific movements important to the population of interest were measured with the goal of informing future clinical practice and expectations of this technology.

\section{Materials and Methods}

\section{Participants and measurement protocols}

Sixteen SCI individuals attended the indoor therapy centre for the training programme. These participants were aged 21-69 years with SCI between C3 and T12 (ASIS A-D), further information about the participants and their presentation is included in Table 1. All participants gave their consent to participate in the study and for data to be collected and used in the methods described. All participants met the inclusion criteria for safe use of the exoskeleton technology such as functional lower limb ROM, normal or osteopenic bone mineral density, weighing less than $100 \mathrm{~kg}$, medically stable health status, ability to tolerate standing for at least 30 minutes and functioning hands, arms and shoulders (ability to use crutches) [23].

On arrival, participants' passive ROM into ankle dorsi-flexion (DF), hip extension (HE), shoulder internal rotation (SIR) and shoulder extension (SE) was measured by two therapists experienced in working with SCI individuals. Measurements were recorded to the nearest five degrees using a standard goniometer and following the commonly used procedures and joint/bony landmarks for goniometer use and placement at the ranges of interest [24]. Measurements were repeated twice bilaterally at each movement of interest and an average recorded. These same procedures were followed after completion of the training programme. Averaged bilateral data was taken forward for statistical analysis.

\section{The training programme}

The ReWalk ${ }^{\mathrm{TM}}$ is a safe and well tolerated means of robotic assisted ambulation [25]. It is a powered exoskeleton with motorised legs powering passive knee and hip movement, supported by walking aid use with the upper limbs [23] (Figure 1).

Joint angles, gait speed, tilt angle, step delay and mechanistic safety parameters were sized and adjusted to the individual and altered as needed as training progressed. The participants wore a wireless controller around the wrist and the battery and computer in the backpack weighing $3.5 \mathrm{~kg}$ [26].

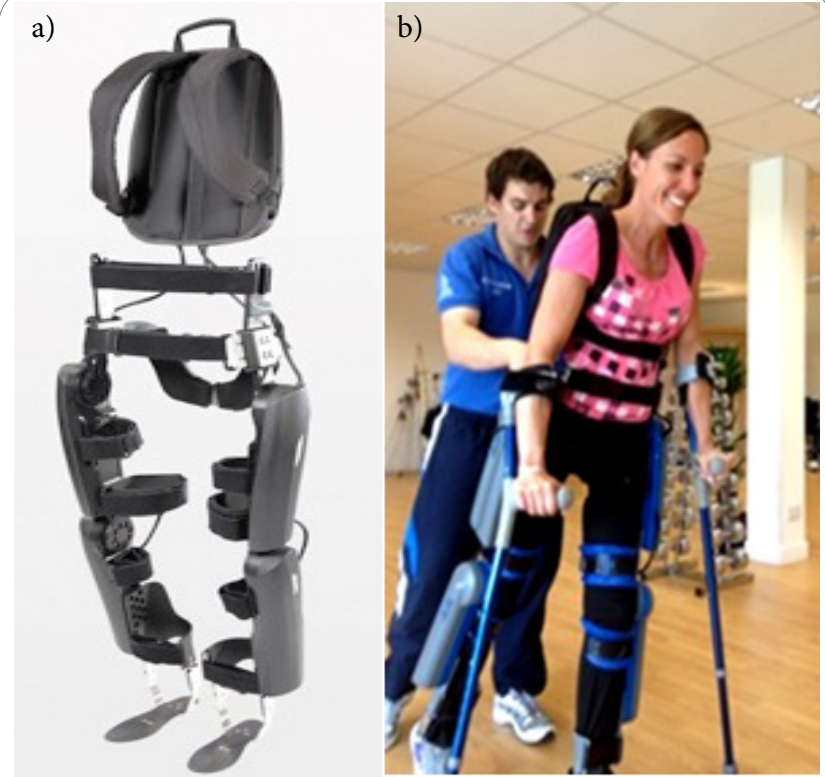

Figure 1: a) The ReWalk ${ }^{\mathrm{TM}}$ exoskeleton [23] and b) as used by a patient.

The training programme took place over five days. In the morning of the first day, after initial measurements, participants spent two hours being educated about and fitted for the exoskeleton as well as completing initial simple therapist assisted sit to stand, and standing balance exercises. On the afternoon of the first day (where possible) participants also undertook simple therapist assisted stepping tasks in parallel bars. Over the next four days participants spent at least four hours in the exoskeleton completing progressive training exercises such as sit to stand, stand to sit, standing balance, step initiation and walking with mastery of crutch use so that therapist assistance and equipment support could be withdrawn as safe practice allowed. At the end of the final day of training ROM was re-measured. Each day participants were prepared for training using standard physiotherapy techniques such as functional electrical stimulation (cycling), appropriate soft tissue techniques and far-infared heat therapy. Additionally, appropriate safety checks were undertaken by therapists at the beginning and end of each day to ensure no injury or damage to skin integrity had occurred. No participants were removed from the study as a result of skin damage or injury.

\section{Data reduction}

Not all ROM measures were available for all participants included in the overall data. Data which was included for each participant is available in table 1. Omissions in ROM data were due to clinical time constraints where therapists used an adequate range check as opposed to goniometry measurement in some cases. For DF $\mathrm{n}=12$, for $\mathrm{HE} \mathrm{n}=$ 14 , for SE $\mathrm{n}=9$ and for SIR $\mathrm{n}=11$.

\section{Statistical analysis}

Statistical analysis was undertaken using IBM SPSS version 20 (NY, USA). Data were checked for normal distribution using Q-Q plots and met this requirement. Data were then analysed using paired $\mathrm{t}$-tests with an accepted significance value of $\mathrm{p} \leq 0.05$. Effect size ( $\mathrm{r}$ ) was calculated from $t$ value [27] and 95\% confidence limits of the difference reported to give an insight into the meaningfulness of any training effect. 
Citation: White HSF, Hayes S, White M (2015) The Effect of Using a Powered Exoskeleton Training Programme on Joint Range of Motion on Spinal Injured Individuals: A Pilot Study. Int J Phys Ther Rehab 1: 102. doi: http://dx.doi.org/10.15344/2455-7498/2015/102

Page 3 of 5

\begin{tabular}{|c|c|c|c|c|c|}
\hline $\begin{array}{l}\mathrm{Pt} \\
\text { Number }\end{array}$ & $\begin{array}{l}\text { Age } \\
\text { (years) }\end{array}$ & Male/Female & $\begin{array}{l}\text { Injury } \\
\text { Level }\end{array}$ & ASIA & $\begin{array}{l}\text { ROM } \\
\text { measured }\end{array}$ \\
\hline 1 & 59 & Male & $\mathrm{T} 8$ & A & $\begin{array}{l}\text { HE, DF, SE, } \\
\text { SIR }\end{array}$ \\
\hline 2 & 26 & Male & C5 & $\mathrm{C}$ & $\begin{array}{l}\text { HE, DF, SE, } \\
\text { SIR }\end{array}$ \\
\hline 3 & 52 & Female & C3 & $\mathrm{C}$ & $\begin{array}{l}\text { HE, DF, SE, } \\
\text { SIR }\end{array}$ \\
\hline 4 & 31 & Female & T3 & A & $\begin{array}{l}\text { HE, DF, SE, } \\
\text { SIR }\end{array}$ \\
\hline 5 & 21 & Male & T7 & $\mathrm{A}$ & $\begin{array}{l}\text { HE, DF, SE, } \\
\text { SIR }\end{array}$ \\
\hline 6 & 41 & Male & $\mathrm{T} 10$ & $\mathrm{~B}$ & $\mathrm{HE}$ \\
\hline 7 & 69 & Male & T7 & $\mathrm{B}$ & $\mathrm{HE}$ \\
\hline 8 & 40 & Male & $\mathrm{T} 12$ & A & $\begin{array}{l}\text { HE, DF, SE, } \\
\text { SIR }\end{array}$ \\
\hline 9 & 29 & Male & $\mathrm{T} 4$ & B & $\begin{array}{l}\text { HE, DF, SE, } \\
\text { SIR }\end{array}$ \\
\hline 10 & 29 & Male & T6 & A & $\mathrm{HE}, \mathrm{DF}$ \\
\hline 11 & 53 & Female & C6 & B & $\begin{array}{l}\text { HE, DF, SE, } \\
\text { SIR }\end{array}$ \\
\hline 12 & 48 & Male & T9 & A & HE, SE, SIR \\
\hline 13 & 41 & Male & C6 & $\mathrm{D}$ & DF, SIR \\
\hline 14 & 44 & Male & $\mathrm{T} 4$ & A & DF \\
\hline 15 & 31 & Male & C6 & $\mathrm{C}$ & $\mathrm{HE}, \mathrm{DF}$ \\
\hline 16 & 44 & Male & $\mathrm{T} 4$ & $\mathrm{~A}$ & HE, DF, SIR \\
\hline
\end{tabular}

Table 1: Participant Demographics, SCI injury presentation and ROM measurements completed.

ASIA Impairment Scale $=$ American Spinal Injuries Association Impairment Scale; $\mathrm{ROM}=$ range of motion; $\mathrm{HE}=$ hip extension; $\mathrm{DF}=$ ankle dorsi-flexion; $\mathrm{SE}=$ shoulder extension; SIR = shoulder internal rotation

\section{Results}

Results are presented with full detail from statistical testing including degrees of freedom and an indication of effect size as well as magnitude of changes pre to post training programme. Due to the amount of available ROM at the different joints results from the ankle and hip are presented together as are those of the shoulder.

Mean ankle DF increased from $1.7^{\circ}$ (plantigrade $\left.=0^{\circ}\right)$ to $6.9^{\circ}(95 \%$ confidence limit, upper $7.3^{\circ}$, lower $3.5^{\circ}$; ( $\mathrm{t}(11)-6.3$; $\left.\mathrm{p}<0.001\right)$ ) which suggested that the participants had significantly greater ROM in this movement post training (Figure 2). A t value of 6.3 represents an $r$ of 0.78 which represents a very large effect size [27].

Mean HE increased from $8.2^{\circ}$ to $14.1^{\circ}$ (95\% confidence limit, upper $9.5^{\circ}$, lower $2.2^{\circ}$; ( $\left.\mathrm{t}(13)-3.5 ; \mathrm{p}=0.004\right)$ which suggested that the participants had significantly greater ROM in this movement post training. A t value of 3.5 represents an $\mathrm{r}$ of 0.49 representing (approximately, large normally $=0.50$ [27] a large effect size .

Mean SE increased slightly from $64.7^{\circ}$ to $66.7^{\circ}$ (95\% confidence limit, upper $13.4^{\circ}$, lower $9.5^{\circ}$; ( $\mathrm{t}(8)-0.39$; $\left.\mathrm{p}=0.705\right)$ which suggested that the participants had not significantly changed their ROM in this movement post training (Figure 3 ). A t value of 0.39 represents an $r$ of 0.02 which represents a very small effect size [27].

Mean SIR increased slightly from $74.3^{\circ}$ to $78.9^{\circ}$ (95\% confidence limit, upper $14.0^{\circ}$, lower $4.9^{\circ}$; ( $\left.(10)-1.07 ; \mathrm{p}=0.31\right)$ which suggested that the participants had not significantly changed their ROM in this movement post training (Figure 3). A t value of 1.07 represents an $r$ of 0.10 which represents a very small effect size [27].

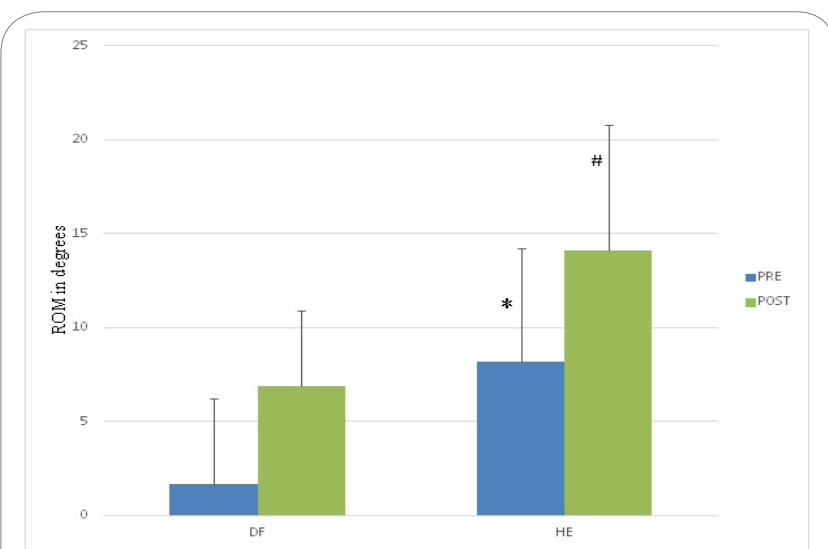

Figure 2: Pre and Post ROM data for ankle dorsi-flexion and hip extension.

${ }^{*}$ Post DF significantly greater ROM than pre $(\mathrm{p}<0.001)$ ROM increased by $5.2^{\circ}$

\#Post HE significantly greater ROM than pre $(\mathrm{p}=0.004) \mathrm{ROM}$ increased by $5.9^{\circ}$

$\mathrm{ROM}=$ range of motion, $\mathrm{PRE}=$ measured before intervention, POST $=$ measured after intervention

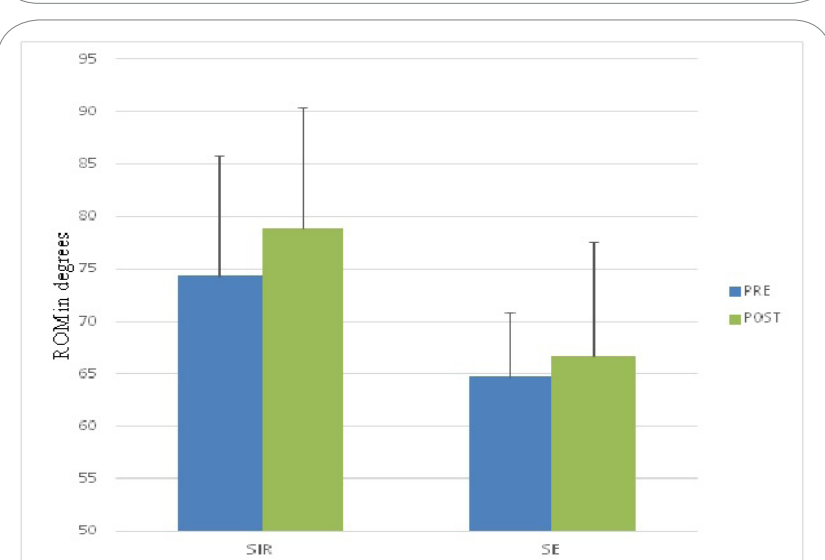

Figure 3: Pre and Post ROM data for shoulder extension and internal rotation.

$\mathrm{ROM}=$ range of motion, $\mathrm{PRE}=$ measured before intervention, $\mathrm{POST}$

$=$ measured after intervention

\section{Discussion}

The aim of this study was to consider pilot data from use of the ReWalk ${ }^{\mathrm{TM}}$ as part of a five day physiotherapy programme aiming to train the user in the novel technology. We measured simple joint ROM in specific movements important to the population of interest with the goal of informing future clinical practice and expectations of this technology. Our main findings were that after the training programme ankle dorsi-flexion ROM had increased significantly by $5.2^{\circ}$ and hip extension by $5.9^{\circ}$ which may have positive implications for ongoing upright and weight bearing therapy as well as ADL in this population. Unfortunately our study did not utilise a control condition and as such we cannot state that the improvements in ROM reported were solely attributable to exoskeleton training, however our improvements did have greater magnitude than those seen in supported standing $[12,15]$.

Our main findings may be at least partially explained through consideration of the reproduction of the gait cycle and impact imposed through use of the powered exoskeleton. Fineberg et al. 
Citation: White HSF, Hayes S, White M (2015) The Effect of Using a Powered Exoskeleton Training Programme on Joint Range of Motion on Spinal Injured Individuals: A Pilot Study. Int J Phys Ther Rehab 1: 102. doi: http://dx.doi.org/10.15344/2455-7498/2015/102

[26] concluded that the gait cycle shown by independent users of the ReWalk ${ }^{\mathrm{TM}}$ exoskeleton was similar to that of 'normal' human gait with regard to kinetic biomechanical analysis of phases. Even assisted users demonstrated 'heel strike' 'mid stance' and 'toe off' phases of the gait cycle which inherently require DF and HE [26]. The cyclical manner of this imposed demand on the joints appears to have resulted in a greater magnitude of DF increase than that reported by Ben et al. [16] of $4^{\circ}$ over 12 weeks of 'tilt table' supported weight bearing therapy. Our confidence intervals for the difference in pre to post scores $\left(7.3-3.5^{\circ}\right)$ were also greater than Ben et al. [16] $\left(2-4^{\circ}\right)$ suggesting a more intense training effect over a much shorter training time. It was difficult to find comparable literature regarding ROM changes seen in $\mathrm{HE}$ in SCI patients using standing and walking devices. Middleton et al. [28] did support the notion that a walking orthosis could at least maintain lower limb joint ROM, however their comments were based upon patient perceptions rather than quantitative data of the joints. The lack of comparable data was surprising since flexion contractures at the hip joint as a result of wheelchair use were highlighted by Karimi [12] as a key health issue for SCI individuals. We theorised that the dearth of literature on this topic may be partially explained because many non robotic walking orthoses types do not replicate bipedal human gait and do not achieve hip extension, rather a less flexed hip position. Our findings may therefore represent a key area of interest for practitioners working with SCI individuals as it appears that the powered exoskeleton achieved ROM increase where it has not been previously reported. Particularly since increased range into HE may help to prevent joint based pathology/deformity at the hip [17]. We did not include a follow up ROM measure to our preliminary study and so cannot comment on the permanency of the changes highlighted for DF and HE. It is likely that these observed changes are reversible and that continued or regular intermittent use of weight bearing powered exoskeleton technology would be required to sustain increased ROM. Further research is required to ascertain a doseresponse relationship for ROM increase and powered exoskeleton usage, despite our positive initial findings.

Our findings regarding changes to shoulder internal rotation and extension were unremarkable. A possible reason for this was that our participants had greater ROM (mean SIR $=74^{\circ}$, mean $\mathrm{SE}=65^{\circ}$ ) in these movements compared to normative data for non SCI individuals (mean SIR $=67^{\circ}$, mean SE $=57^{\circ}$ ) [29]. Theoretically wheelchair use may result in increased ranges of SIR and SE because it is in this combined position that peak shoulder joint loading occurs during the push phase of propulsion [22]. Therefore, the crutch use associated with the ReWalk ${ }^{\mathrm{TM}}$ training may not have induced ROM adaptations in this population. Indeed, only the sit-to-stand and stand-to-sit components of exoskeleton use would place large ROM demands on the shoulders. As such, we considered that powered exoskeleton use should not be expected to result in ROM changes beyond those associated with wheelchair use in SCI individuals.

A final factor to consider when explaining all of our findings was the physiotherapy preparation which occurred prior to powered exoskeleton use. Preparation strategies were selected on an individual basis according to therapist judgement meaning that not all participants received all types of preparation. Nonetheless it was important to consider the potential overlap of effects. Literature in the form of a randomised controlled trial [30] reported that stretching for the ankle plantar flexors was unsuccessful at increasing ankle DF ROM in their sample of 14 SCI patients. We therefore concluded that this type of physiotherapy preparation was unlikely to be responsible for the changes in ROM noted. Conversely, the use of functional electrical stimulation (FES) cycling therapy in a small scale $(\mathrm{n}=5)$ pilot study by Bremner et al. [31] did result in increased 'joint ROM' for three of five participants. Unfortunately these authors did not provide information about the specific type of joint ROM measured, nor the magnitude or significance of any recorded increase. We therefore concluded that there was little evidence to suggest that FES cycling therapy could be responsible for the changes seen in our study though we do acknowledge that there may have been some contribution. A final preparatory strategy used was far infra-red therapy; this modality has been suggested to heat the tissues which could theoretically result in joint ROM change. However there is very little research investigating the specific effects of far infra-red therapy on biological tissues [32] and no evidence suggesting an effect on joint ROM could be found. Overall, we considered that there was a good possibility that the observed ROM changes seen in our study were due primarily to the addition of the powered exoskeleton technology to 'normal' physiotherapy practices.

In the future we plan to expend our pilot study to consider a greater range of physiological parameters which are more mechanistic and relate more closely to the health status of the individual. We are particularly interested in the effect of powered exoskeleton technology on spasticity, postural control and also population specific outcome measures.

\section{Conclusion}

Although this was a pilot study and lacked a control condition, the addition of ReWalk ${ }^{\mathrm{TM}}$ technology was novel as part of a physiotherapy training programme for the powered exoskeleton. Participation in the training programme appeared to result in significant and meaningful increases in ankle DF and HE which were greater than may be expected for other types of weight bearing, upright mobility exercises in this population. Our findings at the hip joint may be of particular interest for informing the clinical expectations of the effect of this type of technology with individuals as there was a lack of comparative information on this important topic area. Overall, our findings were positive and suggested that the training programme may be of benefit to further upright mobility exercise with the population because ankle dorsi-flexion and hip extension are inherently required for normal gait.

\section{Competing Interests}

The authors have declared that no competing interests exist.

\section{References}

1. Albert T, Ravaud JF; Tetrafigap group (2005) Rehabilitation of spinal cord injury in France: a nationwide multicentre study of incidence and regional disparities. Spinal Cord 43: 357-365

2. Pickett GE, Campos-Benitez M, Keller JL, Duggal N (2006) Epidemiology of traumatic spinal cord injury in Canada. Spine (Phila Pa 1976) 31: 799805.

3. Spinal Research (2011). Facts and Figures.

4. van Hedel HJ, Dietz V (2010) Rehabilitation of locomotion after spinal cord injury. Restor Neurol Neurosci 28: 123-134.

5. Ditunno PL, Patrick M, Stineman M, Ditunno JF (2008) Who wants to walk? Preferences for recovery after $\mathrm{SCl}$ : a longitudinal and cross-sectional study. Spinal Cord 46: 500-506 
Citation: White HSF, Hayes S, White M (2015) The Effect of Using a Powered Exoskeleton Training Programme on Joint Range of Motion on Spinal Injured Individuals: A Pilot Study. Int J Phys Ther Rehab 1: 102. doi: http://dx.doi.org/10.15344/2455-7498/2015/102

Page 5 of 5

6. van Middendorp JJ, Hosman AJF, Donders ART, Pouw MH, Ditunno J JF, et al. (2011) A clinical prediction rule for ambulation outcomes after traumatic spinal cord injury: a longitudinal cohort study. The Lancet 377 1004-1010.

7. Bauman WA, Spungen AM (2008) Coronary heart disease in individuals with spinal cord injury: assessment of risk factors. Spinal Cord 46: 466-476.

8. Claydon VE, Steeves JD, Krassioukov A (2006) Orthostatic hypotension following spinal cord injury: understanding clinical pathophysiology. Spinal Cord 44: 341-351.

9. Vette AH, Masani K, Wu N, Popovic MR (2014) Multidirectional quantification of trunk stiffness and damping during unloaded natural sitting. Med Eng Phy 36: 102-109.

10. Ballinger DA, Rintala DH, Hart KA (2000) The relation of shoulder pain range-of-motion problems to functional limitations, disability and perceived health of men with spinal cord injury: A multifaceted longitudinal study. Arc Phy Med Rehab 81: 1575-1581.

11. Edwards WB, Schnitzer TJ, Troy KL (2014) The mechanical consequence of actual bone loss and simulated bone recovery in acute spinal cord injury. Bone 60: 141-147.

12. Karimi MT (2011) Evidence-based evaluation of physiological effects of standing and walking in individuals with spinal cord injury. Iran J Med Sci 36: $242-253$

13. Hornby TG, Zemon DH, Campbell D (2005) Robotic-assisted, body-weightsupported treadmill training in individuals following motor incomplete spinal cord injury. Phys Ther 85: 52-66.

14. Marchal-Crespo L, Reinkensmeyer DJ (2009) Review of control strategies for robotic movement training after neurologic injury. J Neuroeng Rehabil 6: 20 .

15. Newman M, Barker K (2012) The effect of supported standing in adults with upper motor neurone disorders: a systematic review. Clin Rehabil 26: 1059-1077.

16. Ben M, Harvey L, Denis S, Glinsky J, Goehl G, et al. (2005) Does 12 weeks of regular standing prevent loss of ankle mobility and bone mineral density in people with recent spinal cord injuries? Aust J Physiother 51: 251-256.

17. Nicodemo A, Arrigoni C, Bersano A, Massè A (2014) Adult Hip Flexion Contracture due to Neurological Disease: A New Treatment ProtocolSurgical Treatment of Neurological Hip Flexion Contracture. Case Rep Med 2014: 349014.

18. Varoqui D, Patel C, Niu X, Mirbagheri M (2011) Lower limb voluntary movement improvement following robot-assisted locomotor training in spinal cord injury. BIO Web Conferences.

19. Mirbagheri MM, Barbeau H, Ladouceur M, Kearney RE (2001) Intrinsic and reflex stiffness in normal and spastic, spinal cord injured subjects. Exp Brain Res 141: 446-459.

20. Kim CM, Eng JJ, Whittaker MW (2004) Effects of a simple functional electric system and/or a hinged ankle-foot orthosis on walking in persons with incomplete spinal cord injury. Arch Phys Med Rehabil 85: 1718-1723.

21. Eriks-Hoogland IE, DeGroot S, Post MW, Van Der Woude LH (2011) Correlation of shoulder range of motion limitations at discharge with limitations in activities and participation one year later in persons with spinal cord injury. J Rehab Med 43: 210-215

22. Collinger JL, Boninger ML, Koontz AM, Price R, Sisto SA, et al. (2008) Shoulder biomechanics during the push phase of wheelchair propulsion: a multisite study of persons with paraplegia. Arch Phys Med Rehabil 89: 667-676.

23. ReWalk Robotics (2014). ReWalk-Rehabilitation

24. Norkin CC, White DJ (2009) Measurement of Joint Motion: A Guide to Goniometry (4th ed.) Philadelphia: F.A. Davis Company, USA

25. Zeilig G, Weingarden $\mathrm{H}$, Zwecker M, Dudkiewicz I, Bloch A, et al. (2012) Safety and tolerance of the ReWalk ${ }^{\mathrm{TM}}$ exoskeleton suit for ambulation by people with complete spinal cord injury: a pilot study. J Spinal Cord Med 35: 96-101.

26. Fineburg DB, Asselin P, Harel NY, Agranova-Beyter I, Kornfeld SD, et al. (2013) Vertical Ground Reaction Force-based Analysis of Powered Exoskeleton-assisted Walking in Persons with Motor-complete Paraplegia. The J Spinal Cord Med 36: 313-321.

27. Field A (2009) Discovering Statistics Using SPSS (3rd ed.) London: Sage Publications Ltd.

28. Middleton JW, Yeo JD, Blanch L, Vare V, Peterson K et al. (1997) Clinical evaluation of a new orthosis, the 'Walkabout', for restoration of functional standing and short distance mobility in spinal paralysed individuals. Spinal Cord 35: 574-579.

29. Reese NB, Bandy WD (2010) Joint Range of Motion and Muscle Length Testing (2nd ed.), St Louis, Missouri: Saunders Elsevier.

30. Harvey LA, Batty J, Crosbie J, Poulter S, Herbert RD (2000) A randomized trial assessing the effects of 4 weeks of daily stretching on ankle mobility in patients with spinal cord injuries. Arch Phys Med Rehabil 81: 1340-1347.

31. Bremner LA, Sloan KE, Day RE, Scull ER, Ackland T (1992) A clinical exercise system for paraplegics using functional electrical stimulation. Paraplegia 30: 647-655.

32. Vatansever F, Hamblin MR (2012) Far infrared radiation (FIR): its biological effects and medical applications. Photonics Lasers Med 4: 255-266. 